\title{
Introduction: light harvesting for photosynthesis
}

\author{
Anjali Pandit ${ }^{1}$ Ivo H. M. van Stokkum ${ }^{2} \cdot$ Herbert van Amerongen ${ }^{3} \cdot{\text { Roberta } \text { Croce }^{2}}^{2}$
}

Published online: 17 October 2017

(c) Springer Science+Business Media B.V. 2017

The energy from the Sun that strikes the surface of the Earth per hour approximates the human energy consumption of 1 year and supports all life on our planet. Harvesting of sunlight is the first event in the solar-energy conversion process that is carried out by all photosynthetic organisms. Their light-harvesting antennas show large variation in structure and pigment compositions, which enables them to adapt to the light conditions in their natural habitat. Yet, the antennas share an architecture in which all excitations are efficiently transferred to a photosynthetic reaction center. Plants and photosynthetic algae also developed strategies to acclimate to varying light conditions during seasons and can rapidly adjust their antenna sizes in case of excess light, avoiding over-excitation and formation of harmful byproducts. To date, the combination of spectroscopic data with high-resolution structures of various antenna complexes has strongly improved our understanding of the process of excitation energy transfer and inspired design of solar materials (Mirkovic et al. 2017). However, the adaptive and regulatory mechanisms by which light-harvesting antenna systems respond to variations in light intensity and quality, redirect excitation-transfer pathways and dissipate excess excitation energy still have many unsolved questions. At this

Anjali Pandit

a.pandit@lic.leidenuniv.nl

1 Department of Solid-State NMR, Leiden Institute of Chemistry, Leiden University, Einsteinweg 55, 2333 CC Leiden, The Netherlands

2 Department of Physics and Astronomy and Institute for Lasers, Life and Biophotonics, Faculty of Science, Vrije Universiteit Amsterdam, De Boelelaan, 1081 HV Amsterdam, The Netherlands

3 Laboratory of Biophysics, Wageningen University, P.O. Box 8128, 6700 ET Wageningen, The Netherlands point in time, we are faced with a rapidly changing climate, and there is an urgent need to gain in-depth understanding of these light-harvesting processes that eventually can be manipulated to optimize photosynthetic efficiency and ensure plant fitness in fluctuating environments (Croce and van Amerongen 2014; Blankenship et al. 2011; Scholes et al. 2011; Ort et al. 2015).

In this light, we present the special issue on photosynthetic light harvesting containing a selection of the work that was presented at the Light Harvesting Satellite Meeting, held in August 2016 in Egmond aan Zee, The Netherlands, in conjunction with the 17th International Congress on Photosynthesis Research (van Amerongen and Croce 2016). More than 100 researchers from all over the world working in the fields of biophysics, molecular and structural biology, biological, physical and theoretical chemistry of photosynthesis attended this satellite meeting and actively contributed through poster and oral presentations. In particular, many young researchers were given the opportunity to present their work in oral sessions. The meeting sessions, followed by separate discussion sessions, focused on the mechanisms of light-harvesting regulation from molecules to leaves and reported new insights on the dynamics and assembly of light-harvesting superstructures and on photo-physical models for excitation energy transfer and dissipation. Finally, emerging approaches were presented that will advance our understanding of these topics. We were also delighted to incorporate a special evening program that was dedicated to, and organized by, the so-called 49-ers: a generation of prominent scientists, all born in the year $1949 \pm 1$, who pioneered the research field of photosynthetic light harvesting, leading to the wealth of information on light-harvesting structures and processes that we have today. Four historical lectures were given by Richard Cogdell, Graham Fleming, 
Arvi Freiberg and Leonas Valkunas which can be viewed via http://tiny.cc/LH2016Egmond49ers.

We wish to thank all the authors for their contributions to this special issue, the referees for their invaluable comments and feedback on the manuscripts, and all participants of the Light-Harvesting Satellite for the stimulating discussions during the meeting. We greatly acknowledge Terry M. Bricker (Editor-in-Chief) for his invitation to edit this special issue, his support and his assistance, and we are very grateful to Jaap van der Linden of Springer for his help during the production of this special issue. Finally, we are indebted to Michel Olsthoorn for design and maintenance of the LH2016 conference website and we appreciate the support of the Leiden Institute of Chemistry.

\section{References}

Blankenship RE, Tiede DM, Barber J, Brudvig GW, Fleming G, Ghirardi M, Gunner MR, Junge W, Kramer DM, Melis A, Moore TA,
Moser CC, Nocera DG, Nozik AJ, Ort DR, Parson WW, Prince RC, Sayre RT (2011) Comparing photosynthetic and photovoltaic efficiencies and recognizing the potential for improvement. Science 332(6031):805

Croce R, van Amerongen H (2014) Natural strategies for photosynthetic light harvesting. Nat Chem Biol 10(7):492-501

Mirkovic T, Ostroumov EE, Anna JM, van Grondelle R, Govindjee, Scholes GD (2017) Light absorption and energy transfer in the antenna complexes of photosynthetic organisms. Chem Rev 117(2):249-293

Ort DR, Merchant SS, Alric J, Barkan A, Blankenship RE, Bock R, Croce R, Hanson MR, Hibberd JM, Long SP, Moore TA, Moroney J, Niyogi KK, Parry MAJ, Peralta-Yahya PP, Prince RC, Redding KE, Spalding MH, van Wijk KJ, Vermaas WFJ, von Caemmerer S, Weber APM, Yeates TO, Yuan JS, Zhu XG (2015) Redesigning photosynthesis to sustainably meet global food and bioenergy demand. Proc Natl Acad Sci USA 112(28):8529-8536

Scholes GD, Fleming GR, Olaya-Castro A, van Grondelle R (2011) Lessons from nature about solar light harvesting. Nat Chem 3(10):763-774

van Amerongen H, Croce R (2016) Invitation to the 17th international congress on photosynthesis research in 2016: photosynthesis in a changing world. Photosynth Res 127(2):281-284 